\title{
A Querela dos Originais: notas sobre a polêmica entre Sílvio Romero e Teófilo Braga
}

MARÇAL DE MENEZES PAREDES*

\begin{abstract}
Resumo: $\mathrm{O}$ artigo focaliza a polêmica entre dois intelectuais que marcaram a cena cultural luso-brasileira: Silvio Romero e Teófilo Braga. O estudo da intensidade, abrangência e extensão desta polêmica possibilita o delineamento dos termos nos quais se davam as trocas, debates e críticas culturais entre Brasil e Portugal no final do século XIX, além de possibilitar uma reflexão sobre a dimensão escalar da nação como critério histórico utilizado na compreensão de interfaces culturais, imagens que funcionam como instrumentos taxonômicos de memórias nacionais.
\end{abstract}

Abstract: This article focuses the polemic between two important intellectuals on cultural Luso-Brazilian scene: Sílvio Romero and Teófilo Braga. The study of intensity, covering and extension of this polemic make possible to illustrate the subjects which changes, debates and critics were happen between Brazil and Portugal in the ends of nineteen century, beyond allow a reflection about the dimension of the national scale as historic standard used on understanding of interfaces between cultures, images that work as taxonomic instruments of national memories.

Palavras-chave: Cultura brasileira. Cultura portuguesa. Conhecimento histórico.

Key words: Brazilian culture. Portuguese culture. Historical understanding.

\section{A polêmica como forma}

A polêmica é a marca que distingue o relacionamento entre os intelectuais luso-brasileiros do final do século XIX. Trata-se de uma forma de expressão fortemente crítica e explosiva, onde a discussão dá-se tal qual um duelo, de onde não sai ileso um dos dois (ou mais) argumentos em disputa.

Vale lembrar que a palavra polêmica tem sua matriz no idioma grego, sendo um substantivo oriundo do adjetivo polemikós, que significa guerreiro. A polêmica representa uma questão controversa,

* Cientista Social e Mestre em História (PUCRS) e Doutorando em História na Universidade de Coimbra. Bolsista da Fundação para a Ciência e a Tecnologia, Portugal.

Estudos Ibero-Americanos. PUCRS, Edição Especial, n. 2, p. 103-119, 2006 
um debate em forma de luta. Uma guerra de argumentos, portanto. A partir da segunda metade do século XIX, o prestígio dos conhecimentos propagados por Charles Darwin e seus seguidores, condicionados pelas idéias de "luta pela vida" (struggle for life) e pela "sobrevivência do mais apto" (the survival of the fittest), ajuda a compreender o ambiente intelectual que tinha na polêmica sua forma privilegiada de manifestação. ${ }^{1}$

Entretanto, - e em função de uma concepção que vincula o âmbito cultural (o debate de idéias, por exemplo) com o político (as relações entre os intelectuais e a máquina burocrática do Estado) - o estudo das polêmicas ficou, via de regra, caracterizado por ater-se exclusivamente à escala nacional. Este viés tinha, como pano de fundo, a compreensão da polêmica como luta entre setores intelectuais diferentes em busca de assegurar hegemonia para seu discurso em âmbito nacional. ${ }^{2}$ Embora pertinente, esse critério de entendimento das polêmicas em escala nacional acabou por deixar de lado o estudo de debates e polêmicas culturais que, por ventura, pudessem ocorrer em outras escalas referenciais (entre intelectuais de países diferentes). Assim, o escopo "nacional" é o ponto de partida das reflexões sobre a polêmica, não sendo, dessa forma, nunca problematizado.

Desta constatação surge a pertinência - historiográfica e teórica - do estudo da polêmica entre o português Teófilo Braga e o brasileiro Sílvio Romero. Como homens de sua época, tanto um como outro, se envolveram em diversas polêmicas durante suas trajetórias intelectuais. ${ }^{3}$ Embora próximos do ponto de vista teórico, ${ }^{4}$ Silvio

1 Conforme o estudo de Ana Leonor Pereira, a expressão "sobrevivência do mais apto" (the survival of the fittest) é de Herbert Spencer mas foi introduzida por Charles Darwin como sinónimo da sua ideia de "selecção natural" (natural selection) a partir da 5 $5^{\text {a }}$ edição do seu A Origem das Espécies (1869). Embora a Teoria da Evolução de Herbert Spencer seja diferente da Teoria da Descendência com Modificações defendidas por Charles Darwin, ambas faziam parte de uma mesma configuração científica, justificando-se assim o seu uso conjunto neste caso. Para maiores informações PEREIRA, Ana Leonor. Darwin em Portugal. Filosofia. História. Engenharia Social. Coimbra: Almedina, 2001.

2 Como afirma Revel: “dans sa version 'classique', l'histoire sociale s'est très majoritariement conçue comme une histoire des entités sociales: la communauté de résidence (village, paroisse, ville, quartier, etc.), le groupe professionnel, l'ordre, la classe. De ces entités, on pouvait certes discuter les contours et, plus enconre, la cohérence et la signification socio-historique, mais on ne les remettait pas fondamentalement en cause. D'où l'impression, en parcourant l'énorme capital de connaissances accumulé pendant trente ou quarante ans, d'une sorte de déjà vu et d'inertie classificatoire". Jacques Revel. La Micro-analyse et construction du social In: Jeux d'échelles: la micro-analyse à l'experience. Textes rassemblés et présentés par Jacques Revel. Paris : Gallimard, 1996, p. 22-23.

3 Romero entrou em polêmica com muitos intelectuais de sua época, tais como Araripe Júnior, José Veríssimo, Manoel Bonfim. As obras de Roberto Ventura Estilo Tropical. História cultural e polémicas literárias no Brasil 1870-1914. São Paulo: Companhia 
Romero e Teófilo Braga tiveram uma intensa polêmica ao longo de vários anos, incluindo, nesta contenda, outros autores da época. Particularmente entre eles, percebe-se um debate intenso em vários níveis, onde se articulam conceitos e preocupações teóricas e políticas que se dão em escala extra-nacional. Numa palavra: o estudo da polêmica entre Sílvio e Teófilo permite lançar um olhar atento a novas escalas de referência - neste caso a escala luso-brasileira - para o estudo das trocas culturais no final do século XIX. ${ }^{5}$

Dito isto, vale chamar atenção para a peculiaridade da polêmica entre Romero e Braga: a questão dos direitos intelectuais/ autorais do critério nacional e etnológico para o estudo da História da Literatura nos países de Língua Portuguesa.

\section{Uma polêmica luso-brasileira}

A obra de Teófilo Braga já era conhecida por Silvio Romero bem antes do início da polêmica. Já no primeiro texto publicado por Romero, quando de sua transferência para o Rio de Janeiro, ${ }^{6}$ na Revista Brasileira, em 1879, constam uma série de considerações acerca da obra de Teófilo Braga. Mencionando especificamente as obras Manual de História da Literatura Portuguesa e Cancioneiro e

das Letras, 1991, e de Maria Aparecida Rezende Mota Silvio Romero, dilemas e combates no Brasil da virada do século XX. Rio de Janeiro: Editora FGV, 2000, são importantes referências nesse sentido. Teófilo, por sua vez, polemizou com Alexandre Herculano, Oliveira Martins, Pinheiro Chagas, entre outros. Sobre seu pensamento consultar o trabalho de HOMEM, Amadeu Carvalho. O Positivismo em Portugal: o contributo de Teófilo Braga. Coimbra: Minerva, 1989, bem como o capítulo de Fernando Catroga "Positivistas e Republicanos". In: TORGAL, Luís dos Reis; MENDES, José Amado; CATROGA, Fernando. História da História em Portugal. Séculos XIX e XX. Volume I - A História Através da História. Coimbra: Temas e Debates, 1998. Sobre as polémicas em Portugal consultar As grandes polêmicas portuguesas. Lisboa: Verbo, 2 v. 1964-1967.

4 Para citar apenas alguns pontos em comum, vale lembrar que ambos defendiam ardorosamente posições anti-metafísicas para o estudo da história, bem como o critério etnológico nacional para a análise das literaturas nacionais. A esse respeito merece consulta as Atas do III Colóquio Tobias Barreto. Lisboa: Instituto de Filosofia LusoBrasileiro, 1996, assim como a obra de Paulo Borges Pensamento Atlântico, estudos e ensaios de pensamento luso-brasileiro. Lisboa: Imprensa Nacional Casa da Moeda, 2002.

5 Revel "voit dans les principe de variation d'échelle un ressource d'une exceptionelle fecondité, parce qu'elle rend possible la construction d'objects complexes et donc la prise en compte de la structure feuilletée du social. Elle pose du même coup qu'aucune échelle n'a de privilège sur une autre, puisque c'est leur mise en regard qui procure le plus fort bénéfice analytique". REVEL, loc. cit., p. 13.

6 Câmara Cascudo ressalta a importância que essa transferência teve na trajectória intelectual de Romero. CASCUDO, Luís da Câmara. Epígrafe e Nota bibliográfica. In: ROMERO, Sílvio. Estudos sobre a Poesia Popular do Brasil. Petrópolis: Vozes, Colecção Dimensões do Brasil, 1977. 
Romanceiro Geral de Teófilo Braga, Romero afirma que o pensamento de Braga "de romântico histérico e de metafísico idealista deu um salto mortal para o positivismo?"7 $\mathrm{O}$ autor sergipano reconhecia, entretanto, que Braga, "apesar de seus arrojamentos gratuitos, tem mais senso crítico do que o geral dos seus compatriotas". ${ }^{8}$

Pelo trecho acima, já é possível perceber que Romero operava sua demarcação da atmosfera intelectual portuguesa. ${ }^{9}$ Entretanto, na mesma edição da Revista Brasileira, Silvio Romero menciona sua dificuldade em publicar no Rio de Janeiro seus textos que continham o critério etnológico e histórico de classificação da literatura brasileira. Assim, em 1879, faz a seguinte consideração: "em nossa obra, - ainda inédita, - Cantos e Contos do povo brasileiro - recolhidos da tradição, já pronta, e que é o trabalho mais completo que possuímos no gênero, não tem podido ser publicado por falta de um editor" ${ }^{10}$ Como se vê, faltava espaço para a divulgação de sua obra. Esse espaço de veiculação Romero acabaria encontrando em Portugal.

Esse fato, aparentemente simples, permite-nos uma reflexão. Ora, toda obra de Silvio Romero é fortemente nacionalista. Suas preocupações giravam em torno da busca do "genuíno nacional". Conforme o autor afirmava, ainda em 1879, em sua classificação da literatura brasileira, seriam incluídos apenas os autores que representassem um princípio qualquer de "diferenciação nacional". Nesse grupo, para Romero, apenas Gregório de Matos, Tomás António Gonzaga, Santa Rita Durão, Martins Pena, Alvares de Azevedo e Tobias Barreto poderiam estar incluídos.

Contudo, é importante chamar atenção que, em Portugal, também havia um intelectual de importância a capitanear as preocupações acerca do estudo da Literatura Nacional, tendo como preocupação central a definição da lusitanidade a partir da diferenciação portuguesa (em relação ao resto da Ibéria). Chamava-se Teófilo Braga. Foi ele o organizador e prefaciador da primeira edição dos Cantos e dos Contos Populares do Brasil, feita em Portugal.

7 ROMERO, Silvio. A poesia popular no Brasil. In: Revista Brasileira, ano 1, tomo 1, 1879, p. 194.

8 ROMERO, Silvio. A Literatura Brasileira; suas relações com a portuguesa; o Realismo. In: Revista Brasileira, ano 1, tomo 2,1879, p.281.

9 Romero dizia que, a partir do Romantismo, "o velho reino perdeu definitivamente o encanto a nossos olhos". A literatura brasileira... loc. cit., p.281.

10 ROMERO, Silvio. A poesia popular no Brasil, loc. cit., p.266. 
Entenda-se o ambiente: numa atmosfera de preocupações com a delimitação dos contornos das culturas nacionais, a publicação de Romero em Portugal fez acender um importante nó-crítico que envolvia a definição de cada uma das culturas nacionais, posto que implicava a redefinição dos limites entre as culturas brasileira e portuguesa. A este tema voltaremos adiante. Primeiro importa relatar alguns contornos da polêmica aberta.

O início da polêmica acontece por ocasião da publicação, em Portugal, dos Cantos Populares do Brasil, em 1883, e dos Contos Populares do Brasil, em 1885. Ambos textos de Silvio Romero. Por intermédio do livreiro Carrilho Videira, ${ }^{11}$ Teófilo Braga, já na época respeitado professor, é convidado a fazer um estudo introdutório à edição dos Contos do intelectual brasileiro. ${ }^{12}$ Conforme a versão de Romero, o fato agravante disto está que Teófilo, nesse estudo, tenha "se apoderado" de seu critério e modificado partes de sua obra. Assim, e em tom virulento, Romero escreve um protesto à atitude de Braga. Publica Uma Esperteza. Os Cantos e Contos Populares do Brasil e o Sr. Teófilo Braga. Protesto.

Vale ressaltar que o texto publicado por Teófilo Braga, como introdução à obra de Romero, fora também publicado como parte integrante de uma outra obra sua, os Contos Tradicionais do Povo Português.13 Este escrito - introdução à obra de Romero e subcapítulo de uma obra sua - chamava-se (Sobre a) Novelística brasileira. Nele, Teófilo afirmava que a colonização brasileira representa um "fenômeno conjuntamente étnico e sociológico" de grande relevo. Para Romero, Teófilo cometera os seguintes "delitos" na elaboração de seu estudo introdutório à publicação dos seus Contos em Portugal: cortar um trecho da Advertência preliminar do livro em que ele dava conta da classificação feita; apoderar-se dessa divisão etnográfica dos contos brasileiros e dá-la como produção original sua; fingir trabalho próprio, passando alguns contos tupis, conforme Romero, para a seção de contos africanos; incluir no livro os Contos tupis de Couto de Magalhães; e, por fim, escrever um prólogo "disparatado, inçado de erros trapentos, em oposição absoluta aos meus próprios Estudos sobre a poesia popular brasileira,

11 Romero teve muitas obras publicadas em Portugal, geralmente pelo livreiro Carrilho Videira, da Nova Livraria Internacional. Atualmente trabalho num estudo sobre a inserção da obra de Romero em Portugal.

12 ROMERO, Silvio. Contos populares do Brasil. Coligidos pelo Dr. Silvio Romero; com um estudo preliminar e notas comparativas por Teófilo Braga. Lisboa: Nova Livraria Internacional, $1^{\text {a }}$ edição, 1885.

13 BRAGA, Teófilo. Contos Tradicionais do Povo Português. Vol. 1. Lisboa: Dom Quixote, 1883. 
que são o manancial onde o compilador açoriano foi beber o poucochinho que sabe sobre a literatura popular desta parte da América". ${ }^{14}$ Para Romero, trata-se de um "flagrante delito de charlataneria literária". 15

Para melhor aquilatarmos as coisas, é importante relatar que Teófilo admitia a modificação de partes do texto de Romero. Ainda na primeira edição, de Lisboa, em 1885, em nota de rodapé, esclarece: "Modificamos neste ponto o plano do coletor, completando a representação dos elementos étnicos do Brasil com o que atualmente se conhece de tradições dos indígenas". ${ }^{16}$

Essa consideração do intelectual português nos permite melhor asseverar a virulência da denúncia de Romero. Seria ela advinda exclusivamente de um caso de quebra de direitos autorais ou estaria relacionada à natureza própria das questões relacionadas à escala nacional de definição das culturas brasileira e portuguesa? Seria este um caso de "alucinação dos limites" de que nos fala Rui Cunha Martins?

Nesse ambiente, vale ressaltar que a resposta formal de Teófilo Braga demorou alguns anos. Treze anos depois da publicação de Uma Esperteza (1887) por Romero, Teófilo, em carta colocada em apêndice à obra $O$ Sr. Sílvio Romero e a Literatura Portuguesa, de seu discípulo Fran Paxeco (1900) faz sua declaração acerca do ocorrido. ${ }^{17}$ De posse de algumas cartas pessoais de Carrilho Videira, Teófilo expõe missivas que Romero tinha enviado ao livreiro. Por exemplo, uma carta de Romero de novembro de 1882 onde agradece a Carrilho Videira e Braga por "terem salvado das traças esta coleção"; ou outra, de 8 de abril de 1884 onde Romero, segundo a transcrição de Teófilo, teria pedido a Braga o prefácio (o que Romero nega em Uma Esperteza), bem como teria escrito que "a única coleção de mérito é a de Teófilo". 18

Ainda nesta carta-resposta a Romero, Teófilo informa que teve notícia e leu Uma Esperteza porque esta obra lhe fora enviada

14 ROMERO, Sílvio. Uma Esperteza. Os Cantos e Contos Populares do Brasil e o Sr. Teófilo Braga. Protesto. Rio de Janeiro: Tipografia da Escola, de Serafim José Alves, 1887, p. 11-12.

15 ROMERO, Silvio. Uma Esperteza... loc. cit., p.13.

16 BRAGA, Teófilo. Sobre a Novelística Brasileira, In: ROMERO, Silvio. Contos populares do Brasil. Lisboa: Nova Livraria Internacional, 1. ed., 1885, p. V.

17 BRAGA, Teófilo. Carta de Teófilo Braga a Fran Paxeco. In: PAXECO, Fran. O Sr. Sílvio Romero e a Literatura Portuguesa. Maranhão: Editores A. P. Ramos d'Almeida \& C. Suces., 1900

18 Informações retiradas da Carta de Teófilo Braga. In: PAXECO, Fran. O Sr. Silvio... loc. cit., p.194-195. 
pelo próprio Fran Paxeco. ${ }^{19}$ E mais: pelo informado, a cartaresposta a Romero foi escrita especificamente a pedido e para constar mesmo no livro de Fran Paxeco. Pergunta-se, então: qual era o tom do livro Fran Paxeco O Sr. Silvio Romero e a Literatura Portuguesa?

Paxeco intensificou o tom de acusações e ofensas pessoais em sua obra. ${ }^{20}$ Na maioria das vezes, considera que Romero não gosta de Teófilo simplesmente por este ser português. Para Fran Paxeco, o "crítico sergipano volta um ódio de morte a todos os vultos literários da velha Lusitânia; e essa ojeriza, sem razão de ser, leva-o às vezes a afirmar certas proposições absurdas e paradoxais". ${ }^{21}$ Seu livro, entretanto, e apesar das farpas e acusações duvidosas, desnuda toda uma série de relações existentes entre os grupos que circundavam Teófilo e Romero. Vale grifar: esse grupos eram extra-nacionais. Atentemos às marcas do livro de Paxeco: ele é dedicado "à memória de Adolfo Caminha", à Teixeira Mendes, "o maior pensador que o Brasil produziu até hoje", à Júlio de Castilhos, o primeiro entre os primeiros estadistas brasileiros, em todos os tempos", entre outros.22 Que ilações tirar dessa verdadeira rede de relações?

\section{Extensão e abrangência}

Antes de mais nada, importa perceber o alcance de uma perspectiva que amplia o foco de análise das relações culturais para além das balizas nacionais. Com esse procedimento, foi possível perceber, por exemplo, que as relações entre Romero e Teófilo faziam parte (tendo neles as figuras intelectualmente mais destacadas) de uma complexa e ampla plêiade lusobrasileira de relacionamentos culturais. ${ }^{23}$

19 A informação é confirmada, por exemplo, nas cartas de Teófilo para Paxeco de 01/07/1900 e 26/01/1901. Ver PAXECO, Fran. Cartas de Teófilo Braga (com um definitivo trecho autobiográfico do Mestre e duas "confissões" de Camilo). Lisboa: Portugália, 1924.

20 "Uma cabaça - eis o que é a cabeça de Sílvio! E, como tal, cremos ser efetivamente a primacial do Brasil, por ser precisamente a mais oca", PAXECO, Fran. O Sr. Silvio... loc. cit., p. 13.

21 PAXECO, Fran, O Sr. Silvio... loc. cit., p.89.

22 PAXECO, Fran. O Sr. Sílvio Romero e a Literatura Portuguesa, loc. cit., folha de rosto.

23 A idéia de "plêiade" luso-brasileira é muito bem desenvolvida por BERRINI, Beatriz. Brasil e Portugal: a Geração de 70. Porto: Campo das Letras, 2003. 
Após a publicação da carta-resposta, em apêndice à obra de Fran Paxeco, Sílvio Romero não tarda muito em dar-lhe uma réplica. Estampa, então, em 1904, Passe Recibo (Réplica a Teófilo Braga). ${ }^{24}$ Esta obra se afigura de largo interesse para nosso estudo, pois revela também mais traços da arquitectura desta polêmica. Ao contrário de Uma Esperteza, e como que em resposta na mesma moeda, esta réplica de Sílvio Romero veio precedida de um estudo introdutório, intitulado "Duas Palavras", assinado por Augusto Franco. ${ }^{25}$ Neste texto introdutório, Franco ataca diretamente Fran Paxeco, censurando seu "vocabulário repelente e nojento" e "próprio de lupanares" em "agredir garotamente a vultos tão brilhantes das letras brasileiras". Por isso, diz ainda, "nem Silvio Romero, nem qualquer outro tão canalhamente insultado por Fran Paxeco, lhe respondeu as chalaças, nem as responderá jamais, porque, aqui, se não dá pasto". ${ }^{26}$

Vale chamar atenção que, apesar da ressalva de Augusto Franco, Romero acusou o golpe dado por Fran Paxeco (que afirmava sua ojeriza a tudo que vinha de Portugal). Romero, ainda na folha de rosto, ressalta: "A questão particular, que debato com o Sr. Teófilo Braga, em nada altera a alta simpatia que voto à nobre Nação Portuguesa". ${ }^{27}$ Sílvio Romero ressalva: "o meu debate é com o Sr. Teófilo Braga e só com ele". ${ }^{28}$

É relevante este fato: pelo exposto, configura-se uma relação de hierarquia intelectual entre as facções da polêmica. Na contenda, não se permite a quebra da hierarquia intelectual, a mistura entre "grandes vultos" e "discípulos". Como fica claro de perceber, ao nível de Sílvio Romero está Teófilo Braga e, abaixo deles, na condição de discípulos e divulgadores, estão Fran Paxeco e Augusto Franco. Ou seja, a partir destas informações, é possível estabelecer níveis de importância e de circulação das idéias e das trocas culturais em âmbito luso-brasileiro.

24 ROMERO, Silvio. Passe Recibo (Réplica a Teófilo Braga). Publicação dirigida por Augusto Franco. Belo Horizonte: Imprensa Oficial do Estado de Minas Gerais, 1904.

25 Augusto Franco foi crítico literário em Minas Gerais. Sob o pseudónimo "Aufra", assinava crónicas nos jornais Correio de Minas e Jornal do Comércio, em Juiz de Fora. Ver NOBREGA, Dormevilly. Prosadores. Colectânea. v. 1. Juiz de Fora: Fundação Cultural Alfredo Lage, 1982, p.99-100.

26 FRANCO, Augusto. Duas Palavras. In. ROMERO, Silvio. Passa Recibo, loc. cit., p. 1011.

27 ROMERO, Silvio. Passe Recibo... loc. cit., folha de rosto.

28 ROMERO, Silvio. Passe Recibo... loc. cit., p.22. 
Merece destaque a importância da análise das obras dos discípulos e divulgadores para a compreensão das relações culturais entre Brasil e Portugal, no final do século XIX. No caso da polêmica estudada, as obras de Fran Paxeco para Teófilo e de Augusto Franco para Silvio Romero têm especial importância no sentido de estabelecer os níveis de circularidade de idéias, a hierarquia intelectual, bem como a recepção dos autores pela comunidade letrada da época.

Fran Paxeco é, junto com Teixeira Bastos, um dos principais seguidores de Teófilo Braga. A análise de seus livros é importante no sentido de melhor entender a divulgação e a recepção da obra de Teófilo no Brasil. ${ }^{29}$ Como cônsul português, editou vários textos na defesa e divulgação de seu mestre, além de o informar sobre a recepção e discussão de seus livros no Brasil. De suas obras, merece destaque, além de $O$ Sr. Sílvio Romero e a Literatura Brasileira, editada no Maranhão, em 1900, seu importante livro Teófilo no Brasil, editado em Lisboa em 1917. Fran Paxeco manifestava-se praticamente como um defensor dos interesses portugueses no Brasil, organizando, inclusive, cerimônias em homenagem a Teófilo Braga. ${ }^{30}$ Por isso, não surpreende que tenha tomado parte na polêmica através de insultos e críticas picantes à postura de Silvio Romero.

Vejamos outro caso que atesta a extensão e a abrangência da polêmica: Augusto Franco. $\mathrm{O}$ crítico literário mineiro e admirador de Romero, em sua coluna no Jornal do Comércio, de Juiz de Fora, por sua vez, entra em choque com Teófilo. Em matéria publicada por ocasião das cerimônias em homenagem ao $259^{\circ}$ aniversário da independência portuguesa (também $7^{\circ}$ aniversário da Real Sociedade Auxiliadora Portuguesa da cidade), Augusto Franco - assinando pelo pseudónimo Aufra - relata que Zeferino Cândido, jornalista homenageado na cerimônia, havia lhe contado o seguinte acontecimento: "foi o caso que, tendo falecido o profundo investigador da História de Portugal [Alexandre Herculano], Th. Braga se dirigiu ao Dr. Zeferino e pronunciou mais ou menos estas palavras interrogativas e decisivas: - Sabe quem morreu? O Herculano, aquele adulador (!)... A resposta foi um tabefe tão bem puxado e certeiro que deitou Braga por terra»".31 Pouco mais de três meses depois, Augus-

29 Conforme carta de 14/11/1901, onde Braga agradece a Paxeco por este se prontificar a "cumprir a missão de Teixeira Bastos" na divulgação de sua obra. In: PAXECO, Fran. Cartas de Teófilo... loc. cit., p.48-51.

30 Como atesta carta de 12 de outubro de 1900 de Teófilo Braga, onde ele agradece Fran Paxeco pela homenagem recebida por ele do Centro Caixeral do Maranhão em cerimônia realizada em 28/07/1900. In: PAXECO, Fran. Cartas de Teófilo... loc. cit., p. 2428.

31 Jornal do Comércio, Juiz de Fora/MG, 2 dez. 1899, p. 1. 
to Franco publicava em sua coluna uma carta-resposta de Teófilo Braga - carta enviada a Eugênio Silveira, diretor da União Portugue$s a$. Neste texto, o autor português faz referência à coluna de A. Franco do Jornal do Comércio, que lera em Lisboa. Teófilo, além de negar o relatado no Jornal do Comércio de Juiz de Fora, afirma que "bordar sobre isso lendas de boêmia literária a que nunca pertenci, é de uma infelicidade que raiva pela imbecilidade". 32

Como se vê, a polêmica era bastante abrangente. Seu estudo revela a existência de uma considerável circulação de idéias no eixo luso-brasileiro. As farpas trocadas, entretanto, não se resumiam simplesmente aos personagens em disputa. Sua análise permite estabelecer eixos de relacionamento entre os dois países, tendo-se atenção aos autores mencionados. Na matéria citada, este foi o caso de Alexandre Herculano. Não espanta, portanto, que Silvio Romero tenha dedicado a Herculano e Antero de Quental a publicação de sua obra A Pátria Portuguesa, o território e a raça, onde critica fortemente a tese de Teófilo Braga sobre a formação da nacionalidade portuguesa. ${ }^{33}$ Ressalte-se, nesse sentido, que tanto Antero como Herculano também haviam polemizado com Teófilo Braga. Romero, com isso, busca filiar-se à facção dos opositores de Teófilo também em Portugal. Eis aí mais uma marca extra-nacional da polêmica, além de uma informação sobre as balizas da entrada de Romero na rede intelectual portuguesa.

Há, ainda, uma outra questão relevante a ser considerada. Tanto Romero quanto Teófilo, em suas réplicas e tréplicas, mencionam informações tiradas, estritamente acerca dos textos um do outro, de fontes outras que não as brasileiras nem portuguesas. Considera Romero: "falo ao meu país e o faço provocado por uma revista espanhola de Sevilha - Boletin Folklórico Español, que não sabendo dos fatos, bateu palmas às escamoteações do professor açoriano". Menciona ainda a revista Polyblion, de Paris. Por sua vez, Teófilo afirma que "por alguns compte-rendu, publicados em revistas francesas e italianas, em 1887, é que soube da existência do livro do Sr. Sílvio Romero - Uma Esperteza". ${ }^{34}$

32 Jornal do Comércio, Juiz de Fora/MG, 15 fev. 1900, p. 1.

33 ROMERO, Silvio. A Pátria Portuguesa, o território e a Raça. Apreciação do livro de igual título de Teófilo Braga. Lisboa. Livraria Clássica Editora de A. M. Teixeira, 1906. Teófilo Braga defendia a pertinência do critério racial na compreensão da nacionalidade portuguesa. Contra ele, polemizou Herculano e, principalmente, Oliveira Martins. Ambos defendiam que Portugal teria sido formado por vontade política dos reis, e não por determinação racial ou territorial.

34 ROMERO, Silvio. Uma Esperteza... loc. cit., 13 e BRAGA, Teófilo. Carta de Teófilo Braga In: PAXECO, Fran. O Sr. Silvio... loc. cit., p. 191. 
Recuperemos, assim, os contornos da polêmica. Pelo exposto, é possível perceber a extensão da contenda entre Romero e Braga por mais de duas décadas. Também está bom de ver que a polêmica foi bastante abrangente na medida em que incluiu os seguidores e discípulos de cada um dos intelectuais mencionados. A troca de farpas e referências entre os autores e seus textos remete para um conjunto de revistas e autores mencionados que, inclusive, transbordam os referenciais nacionais, referindo-se, antes, a uma circularidade cultural extra-nacional que tinha, na definição das nacionalidades - brasileira e portuguesa - sua razão de ser.

\section{O critério nacional}

Apesar da intensidade da polêmica, tanto Silvio Romero como Teófilo Braga estavam voltados para a mesma questão de definição dos contornos que definiam suas nacionalidades. Ressalte-se que ambos concordavam também quanto à importância da ruptura com interpretações metafísicas nesse processo de delimitação entre culturas e nações. Para uma melhor compreensão desse contexto, é importante referir sobre um projecto conjunto que tiveram, antes da polêmica.

Trata-se da publicação da revista Estudos Livres, que tinha como objetivo principal "reatar a aliança mental luso-brasileira", num contexto de "crise de transformação mental e política em que vão entrando as duas nacionalidades portuguesa e brasileira", a partir da divulgação de investigações que "conduzam para um ponto de vista social". ${ }^{35}$ A revista Estudos Livres tinha dupla diretoria "literário-científica": uma em Portugal e outra no Brasil. Assinavam, pela diretoria portuguesa, Teófilo Braga e Teixeira Bastos; pela diretoria brasileira, Silvio Romero e Karl von Koseritz.

Espreitemos, agora, o lugar ocupado por Karl von Koseritz na polêmica. Parece consensual ressaltar sua importância na divulgação das idéias evolucionistas e cientistas na cena cultural do Rio Grande do Sul. ${ }^{36}$ Sua atividade como propagador das modernas idéias dezenovistas não se resume, entretanto, à dimensão local. Koseritz foi o responsável pela edição, em 1879, da Filosofia no Brasil, obra de Silvio Romero que consistia na apreciação de um

5 Revista de Estudos Livres. Edição 1883-1884. Lisboa: Nova Livraria Internacional, 1884.

36 BARRETO, Abeillard. Bibliografia Sul-Riograndense (A contribuição portuguesa e estrangeira para o conhecimento do Rio Grande do Sul). Volume II (K-Z). Rio de Janeiro: Conselho Federal de Cultura, 1976 e HESSEL, Lothar e outros. O Partenon Literário e sua obra. Porto Alegre: Instituto Estadual do Livro, 1976. 
história do movimento intelectual brasileiro até o estabelecimento da chamada Escola do Recife. Fortalecia, assim, a institucionalização de uma perspectiva que buscava estabelecer as peculiaridades filosóficas brasileiras. ${ }^{37}$

Koseritz, embora guardasse independência intelectual, sempre fez questão de se posicionar ao lado de Romero e Tobias Barreto, na campanha contra a metafísica e a religião como sustentação do saber. ${ }^{38}$ Nesta mesma cruzada antimetafísica, como já o dissemos, estava Teófilo Braga em Portugal. Eis o ponto de contato entre os pólos opostos na polêmica. Seu terreno comum: uma perspectiva cientista de estudo das histórias e culturas nacionais. Em função das mesmas preocupações se compreende o projeto conjunto - luso-brasileiro - da Revista de Estudos Livres. Daí o relacionamento entre ambos. Koseritz entrara também em contato com Braga, como demonstra sua carta, onde agradece a Teófilo "um juízo crítico de inestimável valor, a um pequeno e pouco importante trabalho, como os modestos Bosquejos etnológicos". ${ }^{39}$ Koseritz teve também A Terra e o Homem à luz da Ciência Moderna resenhada, por Teixeira Bastos, nas páginas da Revista de Estudos Livres.

A mencionada obra de Karl von Koseritz - Bosquejos etnológicos - também faz parte da polêmica Teófilo-Romero.40 Trata-se de um estudo que interessava sobremaneira tanto ao português açoriano como ao brasileiro sergipano. Entende-se o porquê. A coletâ-

37 Vale lembrar uma interessante crónica de Araripe Júnior que relata a recepção desta obra de Romero em Portugal. Araripe, citando um trecho do Brasil Mental, de Sampaio Bruno, destaca que quando "Silvio Romero, escrevera e publicara uma espécie de história da Filosofia no Brasil, em Portugal, foi, após o pasmo, um sucesso de gargalhadas. 'Ora isto?!' dizia-se às mesas dos cafés, nas palestras dos jovens curiosos de espírito. 'Com que então: a filosofia do Brasil? Hem? Esta nem o Diabo lembra! Se fosse a carne-seca do Brasil, ou a feijoada do Brasil. Valha-nos Deus!' E riam-se jubilosos da sua insuficiência”. ARARIPE JUNIOR, Tristão de Alencar. Obra Crítica, v. 3 (1895-1900). Rio de Janeiro: Ministério da Educação e Cultura/Casa Rui Barbosa, 1963, p.495.

38 Desde 1876, Koseritz já ressaltava, no editorial do Echo do Ultramar que "nesta cruzada, o dizemos com ênfase, alistamo-nos de todo o coração sob o pendão dos Tobias e Romeros que no Norte do Império já vão encaminhados no que agora encetamos". In: Echo do Ultramar, literatura, ciências e artes. ano 1, n. 1, 1876, Porto Alegre, p. 1.

39 Carta de Koseritz a Teófilo de 22 de dezembro de 1884. In: Quarenta Anos de Vida Literária 1860-1900) - Cartas a Teófilo Braga, com um prólogo "Autobiografia mental de um pensador isolado”. Lisboa: Tipografia Lusitana - Editora Artur Brandão, 1902, p. 210211.

40 Está acessível ao público parte dos Bosquejos etnológicos, no volume organizado por René Gertz. Karl von Koseritz: selecção de textos. Porto Alegre: Edipucrs, 1999 (Colecção Pensadores Gaúchos). 
nea de dados arqueológicos e etnológicos realizada por Koseritz ${ }^{41}$ tinha papel importante na definição da ação portuguesa no contato com os índios brasileiros - e assim propiciava alguns elementos para a definição das características da lusitanidade, que interessava Teófilo -, bem como tinha destaque para Silvio Romero, no sentido de determinar a genuinidade do tipo nacional brasileiro, nomeadamente no que diz respeito às influências indígenas.

Podemos, assim, melhor compreender a acusação feita por Teófilo que Romero teria se apoderado do acervo de Koseritz,42 bem como, por outro lado, conseguimos melhor situar a defesa de Romero que dizia ser Koseritz seu amigo e que este lhe teria cedido o material. ${ }^{43}$ Numa palavra: em relação à polêmica, ora estudada, Karl von Koseritz situa-se a meio caminho. Sua posição permite, contudo, perceber alguns pontos de comunhão entre os polemistas luso-brasileiros, bem como entender quais eram, de fato, as questões que estavam em jogo.

Percebe-se, assim, que até um certo ponto - a necessidade de divulgar os princípios da ciência positiva - estavam todos de acordo. A polêmica, portanto, tem início num segundo nível de preocupações. Começa a tomar força a idéia que o elemento que indispunha Romero e Teófilo não remete à natureza do conhecimento (necessariamente científico para ambos), mas sua função no fortalecimento das balizas de definição e demarcação no âmbito das culturas nacionais brasileira e portuguesa.

Bem vistas as coisas, vale ressaltar a importância da elaboração de uma História da Literatura, seja do Brasil seja de Portugal. O estudo da poesia e da literatura nacionais prende-se à noção de Cultura Popular no âmbito do cientismo historiográfico.44 A Literatura seria a prova factual do sedimentar étnico e moral das épocas que formaram as nacionalidades. Era sua âncora epistêmica. A definição da cultura nacional reforça, assim, o aspecto da soberania cultural no universo de referência luso-brasileiro. Chegamos ao ponto de entender, então, o porquê a questão da originalidade era tão fundamental.

41 A colecção foi praticamente destruída durante a exposição brasileiro-alemã, em 1881.

42 Carta de Teófilo Braga In: PAXECO, Fran. O Sr. Silvio... loc. cit., p. 193.

43 ROMERO, Silvio. Passe Recibo... loc. cit., p. 34-35.

44 Sobre cientismo e história CATROGA, Fernando. Caminhos do fim da história. Coimbra: Quarteto, 2003. 


\section{Originalidade e história}

A temática da originalidade já estava em evidência desde no primeiro artigo de Romero na Revista Brasileira, em 1879. Neste texto, lê-se que "uma nação se define e individualiza quanto mais se afasta pela história, do caráter das raças que a constituíram, e imprime um cunho peculiar à sua mentalidade", por isso, "a nação brasileira, se tem um papel histórico a representar, só o poderá fazer quanto mais se separar do negro africano, do selvagem tupi e do aventureiro português". 45

Desde lá, acontece um processo de amadurecimento intelectual da perspectiva nacionalista que Romero entende fundar nos estudos sobre a literatura nacional. Acredito que o papel atribuído ao mestiço na sua idéia da nacionalidade brasileira deve ser entendido nesse contexto. Afinal, Romero justifica que em sua busca pelo caráter do genuíno nacional, nunca conseguiu entrar em contato com um elemento puro das etnias que formaram o povo brasileiro. Nem índios, nem negros, nem portugueses restaram incólumes ao contato. Frente ao choque de culturas que o experimento colonial português fomentou, não restou nenhuma ontologia étnica intacta. Daí surge o recurso à mestiçagem como a nova e original ontologia da nação brasileira. Entende-se, assim, o porquê escrevia, em 1883, que o transformismo é "a lei que rege a história brasileira". ${ }^{46}$ Nesse sentido é que se justifica a noção da mestiçagem. Para Romero, entenda-se, ela é o resultado da acção da história no Brasil, não sendo, por isso, fruto exclusivo da determinação do território. ${ }^{47}$ É pelo contato social, advindo da história colonial, que o mestiço aparece como força nacional.

Não surpreende, portanto, que na sua principal obra - História da Literatura Brasileira - editada depois do início da polêmica, em 1888, Silvio Romero grave o bordão que lhe dá lugar destacado na história das idéias do Brasil: "Todo brasileiro é um mestiço, quando não no sangue, nas idéias". ${ }^{48}$

45 ROMERO, Silvio. A Literatura Brasileira; suas relações ...loc. cit., p. 273 e 274.

46 ROMERO, Sílvio. Modernas Escolas Literárias. In: Estudos de Literatura Contemporânea. Edição Comemorativa. Organização de Luiz António Barreto. Rio de Janeiro: Imago, 2002, p. 69.

47 É nesse ponto que Romero discorda de Araripe Júnior e com ele também polemiza. A mestiçagem de Romero é resultado histórico, o tropicalismo de Araripe Júnior é determinado pela natureza.

48 ROMERO, Sílvio. História da Literatura Brasileira. Tomo Primeiro. Rio de Janeiro: José Olympio Editora. Coleção Documentos brasileiros, dirigida por Octávio Tarquínio de Sousa. 3ª Edição organizada e prefaciada por Nelson Romero, 1943 [1. ed. 1888], p. $30-40$. 
Mas aonde esse projeto era ameaçado pela ação de Teófilo Braga? Já vimos que o motivo da polêmica entre eles não se resumia à questão da autoria do critério etnológico para o estudo das literaturas nacionais. Se assim fosse, a polêmica talvez nem tivesse iniciado, afinal, como demonstramos, no início do texto, introdutório à primeira edição do livro de Romero em Portugal, o autor português já reconhecia haver modificado o plano inicial da obra.

Mudemos de lado. Vejamos com mais atenção o lugar de Teófilo Braga na história das idéias sobre a nacionalidade portuguesa. No momento em que a polêmica com Silvio se intensifica, desde há muito Teófilo andava às voltas com a idéia da originalidade portuguesa no âmbito das nações da Península Ibérica. Por exemplo, em 1871, publica Epopéia da Raça Moçárabe, aonde vai defender que a nacionalidade portuguesa justifica racialmente a existência de Portugal como nação. Acredito que é no âmbito da distinção nacional que sua teoria do moçarabismo deve ser entendida, pois o moçárabe é, praticamente, um mestiço oriundo do contato entre raças góticas e árabes na faixa de território mais ocidental da Península Ibérica. ${ }^{49}$ Por isso, em 1908, em conferência na Academia das Ciências de Portugal, afirma ter Portugal "originalíssima personalidade". 50

Silvio Romero tinha razão em bradar com violência: se tirassem do seu mestiço brasileiro a originalidade histórica, ele perderia sua razão de ser. Afinal, como ficou claro pelo exposto, o mestiço é a imagem que busca fundamentar a soberania cultural brasileira. Ora, se o português moçárabe também mestiço fosse, então, o brasileiro mestiço seria apenas um herdeiro das características mais peculiares do português. Não se distanciaria de Portugal. Não fundamentaria a cultura brasileira.

Chega-se, assim, à seguinte consideração: a posição na cultura nacional ocupada pelo mestiço, na idéia de cultura brasileira de

49 "Aqui dá-se um curioso fenómeno etnográfico: aparecem as designações geográficas, os nomes de família, a nomeclatura tecnológica, os característicos das autoridades políticas e civis árabes; mas os símbolos poéticos do direito, as tradições épicas, as lendas orais, as superstições são puramente germânicas. Por esta ordem de criações da raça moçárabe se vê a sua constituição fisiológica. Como indomável, o semita cede aquelas qualidades exteriores e visíveis de uma civilização que deslumbra, mas não comunica os sentimentos privativos e orgânicos da raça; por outro lado o godo, como ariano e atraente, não podendo homologar a alma árabe, adopta dela aquilo que se não pode encobrir aos olhos. A designação do Moçárabe, encerra esta noção perfeitamente definida". BRAGA, Teófilo. Epopeia da Raça Moçárabe. Imprensa Portuguesa Editora, 1871, p. 25-26.

50 BRAGA, Teófilo. Plano para a História de Portugal. Antelóquio a PAXECO, Fran. Portugal não é Ibérico. Lisboa: Livraria Rodrigues, 1932, p. 6-7. 
Silvio Romero, é análoga à ocupada pelo moçárabe, na noção de cultura portuguesa de Teófilo Braga. A polêmica e a virulência das acusações trocadas é, assim, filha do processo de definição dos contornos das nacionalidades em contato. $\mathrm{O}$ que se passa entre Romero e Braga é a luta pela originalidade num complexo processo de redefinição de fronteiras memoriais, aonde a assunção da escala nacional, como referência analítica, possui papel primordial. Trata-se de um processo prenhe de "um significativo potencial de turbulência, na medida em que a historicidade inscrita em assuntos de limites e demarcações fomenta, por si só, a coexistência de memórias não coincidentes sobre os instrumentos taxonómicos (marcos, ou outros) que assinalam esses limites". ${ }^{51}$

É importante perceber que tanto o mestiço quanto o moçárabe são imagens que funcionam como instrumentos taxonômicos de memórias nacionais. Uma única alteração provoca todo um rearranjo memorial. Explica-se. O moçárabe tem sua razão de ser na busca de destacar a nacionalidade portuguesa no contexto da Península Ibérica. O mestiço, por sua vez, se justifica distanciando-se da "pureza" racial do índio, do negro e do português aventureiro. Ao se admitir a mistura racial como característica lusitana, tudo o que se disser sobre a mestiçagem racial brasileira terá, necessariamente, relação íntima com Portugal. Aliás, esse era o interesse de Teófilo na coletânea de contos e cantos brasileiros. 52 E o movimento contrário também se pode afirmar. Se entende-se o português no conjunto dos povos ibéricos, fica facilitado o enquadramento do Brasil no quadro dos países latino-americano, uniformizados, assim, pela mesma ação dos colonizadores ibéricos. ${ }^{53}$ Em todos esses casos, do que a história trata? De memória coletiva e da conseqüente redefinição dos limites entre Portugal e Brasil. Daí sua turbulência.

Nessa turbulência dos limites, a originalidade nacional é o moto próprio da polêmica. Como explica Rui Cunha Martins, um conflito interpretativo gera "esforços narrativos tendentes a introduzir alguma inteligibilidade no caos interpretativo produzido por essas memórias concorrenciais, esforços esses no âmbito dos quais

51 MARTINS, Rui Cunha. A Arena da história ou Labirinto do Estado. Cadernos do Noroeste. 15 (1-29), 2001, p. 38.

52 "Quem relancear os dois volumes da História da poesia portuguesa, compreenderá os meus objectivos, quando atirava a impressão dos cantos populares do Algarve, da Madeira, da Galiza, do Brasil, a fim de integrar as desmembradas tradições lusitanas". Carta de 27/11/1905. In: PAXECO, Fran. Cartas de Teófilo, loc. cit., p. 64-67.

53 Essa é a compreensão geral de Manoel Bomfim e seu América Latina males de origem, editado em 1902. 
a narração se constitui em arrolamento ordenador e a própria história toma o caráter de mapa cognitivo da memória. Dir-se-á mesmo, com maior rigor, e tendo em conta o caráter polifônico do registro escrito, que a história, assim convocada e manipulada com intuitos probatórios, surge, neste contexto menos como "mapa" do que como arena". ${ }^{4}$

Completa-se: é nessa arena luso-brasileira da história onde se instituem as balizas referenciais das memórias nacionais portuguesa e brasileira. Por esta compreensão percebe-se que o critério nacional - ao contrário de ser um ponto de partida analítico - é ele mesmo o resultado da institucionalização das identidades nacionais. Afinal, conforme tentamos demonstrar, a escolha da escala referencial da "nação" é produto da turbulência dos limites entre Portugal e Brasil. É seu resultado.

A escolha de uma determinada escala de referência produz efeitos memoriais. A "nação" é, assim, também uma estratégia de conhecimento. 55 Por isso a guerra simbólica pelo critério de originalidade é tão importante. Afinal, a palavra original tem duplo sentido: um, relativo à origem, que remete à idéia de início; outro, relativo à noção de inédito, que não foi copiado de nenhum modelo. Em última instância, a querela dos originais punha em evidência a nação como critério histórico, redefinindo, dessa maneira, as interfaces de contato e de distanciamento entre as memórias coletivas de Portugal e do Brasil.

54 MARTINS, Rui Cunha, loc. cit., idem.

55 Revel considera que "le choix d'une échelle particulière d'observation produit des effets de connaissance et qu'il peut être mis au service de stratégies de connaissainces. [...] C'est le principe de variation qui compte, non le choix d'une échelle particulière". REVEL, Jacques, loc. cit., p. 19. 